\title{
An overview of the role of platelets in angiogenesis, apoptosis and autophagy in chronic myeloid leukaemia
}

\author{
Lisa Repsold ${ }^{1}$, Roger Pool ${ }^{2}$, Mohammed Karodia ${ }^{2}$, Gregory Tintinger ${ }^{3}$ and Annie Margaretha Joubert ${ }^{*}$ (ID
}

\begin{abstract}
Amongst males, leukaemia is the most common cause of cancer-related death in individuals younger than 40 years of age whereas in female children and adolescents, leukaemia is the most common cause of cancer-related death. Chronic myeloid leukaemia (CML) is a chronic leukaemia of the haematopoietic stem cells affecting mostly adults. The disease results from a translocation of the Philadelphia chromosome in stem cells of the bone marrow. CML patients usually present with mild to moderate anaemia and with decreased, normal, or increased platelet counts. CML represents 0.5\% of all new cancer cases in the United States (2016). In 2016, an estimated 1070 people would die of this disease in the United States. Platelets serve as a means for tumours to increase growth and to provide physical- and mechanical support to elude the immune system and to metastasize. Currently there is no literature available on the role that platelets play in CML progression, despite literature reporting the fact that platelet count and size are affected. Resistance to CML treatment with tyrosine kinase inhibitors can be as a result of acquired resistance ensuing from mutations in the tyrosine kinase domains, loss of response or poor tolerance. In CML this resistance has recently become linked to bone marrow (BM) angiogenesis which aids in the growth and survival of leukaemia cells. The discovery of the lungs as a site of haematopoietic progenitors, suggests that CML resistance is not localized to the bone marrow and that the mutations leading to the disease and resistance to treatment may also occur in the haematopoietic progenitors in the lungs. In conclusion, platelets are significantly affected during CML progression and treatment. Investigation into the role that platelets play in CML progression is vital including how treatment affects the cell death mechanisms of platelets.
\end{abstract}

Keywords: Platelets, Chronic myeloid leukaemia, Angiogenesis, Apoptosis, Autophagy

\section{Background}

Amongst males, leukaemia is the most common cause of cancer-related death in individuals younger than 40 years of age whereas leukaemia is the most common cause of cancer-related death in female children and adolescents [1-3]. One-third of all types of cancer identified in children (1 month to 14 years) are attributed to leukaemia of which $78 \%$ are acute lymphoblastic leukaemia (Table 1 and 2) [3].

\footnotetext{
*Correspondence: annie.joubert@up.ac.za

${ }^{1}$ Department of Physiology, Faculty of Health Sciences, School of Medicine, University of Pretoria, Pretoria, Gauteng, South Africa Full list of author information is available at the end of the article
}

Leukaemia results from the abnormal formation of white blood cells during the process of haematopoiesis [4]. Leukaemia can be divided into acute- or chronic leukaemia and is further subdivided as either myeloid (from myeloid cells) or lymphoid (from lymphocytes) leukaemia [4].

The most common types of leukaemia are acute myeloid leukaemia (AML), acute lymphoblastic leukaemia (ALL), chronic myeloid leukaemia (CML) and chronic lymphocytic leukaemia (CLL) [4, 5]. Acute leukaemia refers to the rate at which the disease progresses which is in acute cases is rapid development; without treatment the disease would be fatal within a few months of disease onset. The time of disease progression varies according to 
Table 1 Total estimated number of new leukaemia cases in the United States for 2014 [6]

\begin{tabular}{llll}
\hline Type & Total & Male & Female \\
\hline Acute lymphoblastic leukaemia & 6020 & 3140 & 2880 \\
Chronic lymphocytic leukaemia & 15,720 & 9100 & 6620 \\
Acute myeloid leukaemia & 18,860 & 11,530 & 7330 \\
Chronic myeloid leukaemia & 5980 & 3130 & 2850 \\
Other leukaemia & 5800 & 3200 & 2600 \\
Total estimated new cases & 52,380 & 30,100 & 22,280 \\
\hline
\end{tabular}

Table 2 Estimated deaths (all age groups) from all types of leukaemia in 2014 in the United States [6]

\begin{tabular}{lrrr}
\hline Type & Total & Male & Female \\
\hline Acute lymphoblastic leukaemia & 1440 & 810 & 630 \\
Chronic lymphocytic leukaemia & 4600 & 2800 & 1800 \\
Acute myeloid leukaemia & 10,460 & 6010 & 4450 \\
Chronic myeloid leukaemia & 810 & 550 & 260 \\
Other leukaemia & 6780 & 3870 & 2910 \\
Total & 24,090 & 14,040 & 10,050
\end{tabular}

the type of leukaemia, with accumulation of blood cells that do not mature during haematopoiesis, referred to as blasts $[4,5]$.

Chronic leukaemia is characterised by a long subclinical period ranging from 3 to 5 years, where there is a delayed build-up of abnormal lymphocytes or myeloid cells. The abnormality differs for each type of leukaemia depending on the genetic mutation present, and results in the lymphocytes or myeloid cells not being able to perform their functions. The latter may not be symptomatic for a prolonged period ranging from months to years [4, 5]. Leukaemia can also arise from erythrocytes or platelets resulting in myeloid leukaemia or from the bone marrow, lymph nodes and spleen $[4,5]$.

As previously mentioned, the development of the disease is a result of genetic mutation [7]. Genes involved in the regulation of haematopoiesis are commonly mutated in leukaemia, resulting in differentiation defects of haematopoietic cells. Distinctive mutations are implicated in each type of leukaemia [6-8]. Recurrent cytogenetic abnormalities occur in $50 \%$ of AML patients and $80 \%$ of ALL patients [8]. The rat sarcoma mitogen-activated protein kinase (RAS-MAPK) signalling or phosphatidylinositol 3-kinase (PI3k)/protein kinase B (AKT) signalling allow for proliferation and survival of mutated cells of a haematopoietic origin $[7,8]$.

Treatment and survival rates of leukaemia depend on the type of genetic mutation responsible and stage at time of diagnosis (which varies per leukaemia type). These include radiation therapy, chemotherapy, targeted therapy and combinations of the three treatments (Table 3) [7].

Stem cell transplantation may also be used as treatment in cases of leukaemia and lymphoma [7]. Stem cell transplantation consists of patients receiving initial high dosages of chemotherapy and/or radiation therapy eliminating the bulk of the patient's stem cells, the dosage hereof depends on the type of drug administered. Following this therapy, patients receive a transplant of compatible donor stem cells by infusion, replacing the lost stem cells and producing new, unmutated stem cells [7].

Development of innovative targeted-molecular therapy which comprises of drugs that target molecules including those involved in cell growth signalling, tumour blood vessel development and general markers of apoptosis has transformed treatment of leukaemia and specifically CML through the development of tyrosine kinase inhibitors [9-12].

\section{Chronic myeloid leukaemia}

CML is a chronic leukaemia of the haematopoietic stem cells affecting mostly adults. In 2016 it was estimated that there would be 8220 new cases of chronic myeloid leukaemia and an estimated 1070 people would die of this disease in the United States (Figs. 1, 2) [13]. Chronic myeloid leukaemia represents $0.5 \%$ of all new cancer cases in the United States [13]. CML results from a translocation of the Philadelphia $(\mathrm{Ph})$ chromosome in stem cells of the bone marrow. This, in turn, leads to the collocation of the Abelson murine leukaemia viral oncogene homolog 1 (ABL1) gene from chromosome 9 and the breakpoint cluster region protein $(B C R)$ gene from chromosome 22 [6, 9-12]. The latter causes the fusion of a $B C R-A B L$ gene encoding for the aforementioned transcripts and fusion proteins of the $\mathrm{BCR}-\mathrm{ABL}$ protein including tyrosine-kinase activity involving the phosphorylation of several substrates activating multiple signal-transduction cascades involved in cell proliferation and differentiation [6, 9-12].

Additional genetic events include mutations or deletions of genes namely $p 53$ and the retinoblastoma protein $(R b)$ following the translocation of the $\mathrm{Ph}$ chromosome resulting in the fusion of the $B C R$ and $A B L 1$ genes which allow for the progression of disease [6, 9-12]. The $B C R$ $A B L 1$ gene may function by hindering apoptosis in targeted stem cells [6]. Inhibition of apoptosis in hematopoietic progenitor cells expressing the fused $B C R-A B L$ gene is thought to occur through the phosphotyrosine kinase activity of the $B C R-A B L$ gene. This results in these cells being able to evade dependency on growth factors and resistance to harmful effects of drugs and irradiation $[6,9-12]$. 


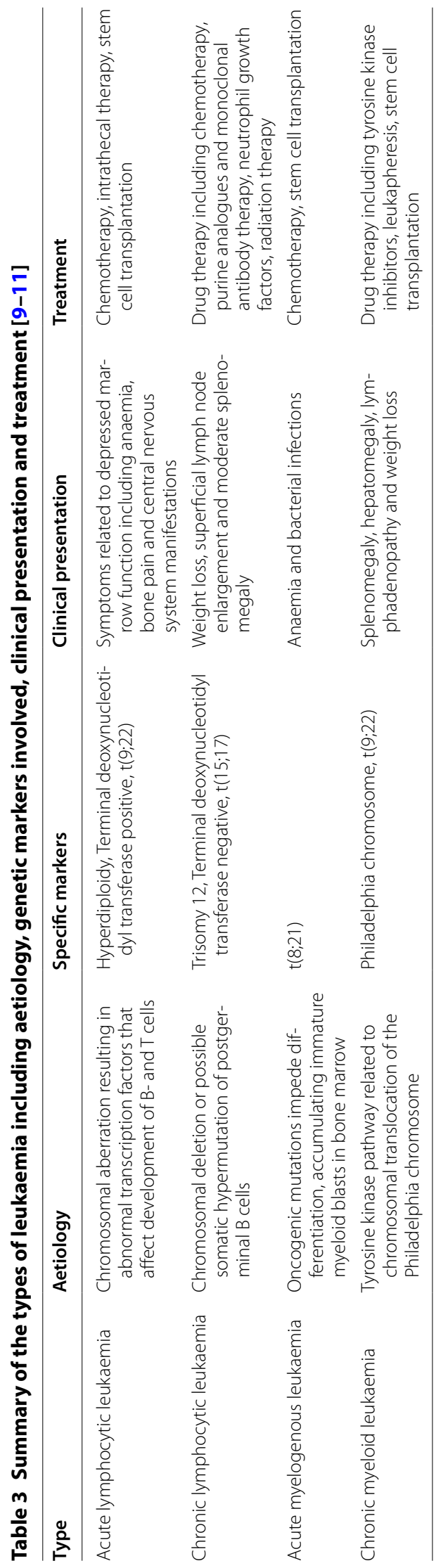




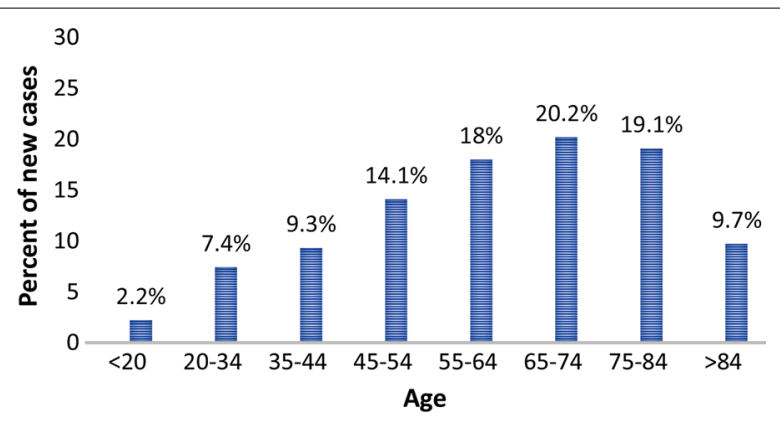

Fig. 1 Percent of new chronic myeloid leukaemia cases in 2016 by age group in the United States [13]

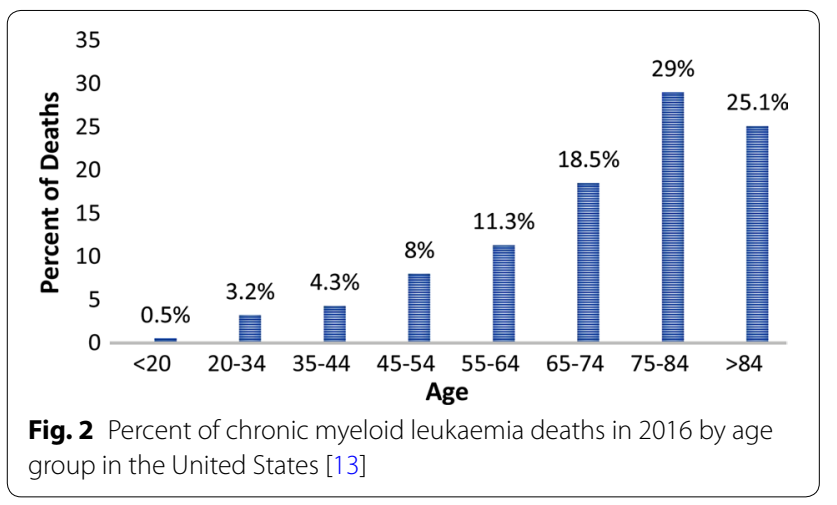

CML can be divided into various phases of disease progression; these are the initial chronic stable phase and advanced phase which are partitioned into the earlier accelerated phase and later acute- or blastic phase [6, 9-12]. The chronic phase is usually the phase in which most patients are diagnosed and is characterized by an increased spleen size, while also being able to maintain a normal range of blood counts as established by comparing to reference levels, on therapy with tyrosine kinase inhibitors [6].

Diagnosis of CML includes the presence of splenomegaly, leukocytosis and the incidence of the $B C R$ $A B L 1$ fusion gene present in leukaemia cells [6, 9-12]. Diagnostic tests include cytogenetic analysis to detect the $\mathrm{Ph}$ chromosome, fluorescence in situ hybridization detecting the presence of the mutated $B C R-A B L$ gene by using fluorescent dyes and the polymerase chain reaction which detects and measures these mutated $B C R-A B L$ oncogenes [6, 9-12].

Progression of CML from the initial, chronic stable phase to the advanced, accelerated and blastic phases is not well understood. Pathways implicated include the atypical phosphorylation of intracellular proteins such as Crk-like protein $(\mathrm{Crkl})$, mitogen-activated protein kinase 1/2 (Mek 1/2), Rac and c-Jun N-terminal kinase (Jnk) [6, 9-12]. The activation of signal transduction pathways rat sarcoma (RAS) or signal transducer and activator of transcription (STAT) may occur [6, 9-12]. The potential activation of the phosphatidylinositol 3-kinase/AKT pathway that enables apoptosis is also implicated [6,9-12].

Research conducted to determine the cause of increased bleeding in patients on TKI treatment showed that Dasatinib and, to a lesser degree Imatinib, inhibit platelet function by impairing arachidonic acid- and epinephrine-induced aggregation. The exact mechanism by which this platelet dysfunction is caused is not known; it was shown not to be related to thrombocytopenia or the presence of clonal haematopoiesis $[14,15]$.

The most widely used treatment for CML is Imatinib, an inhibitor of BCR-ABL tyrosine kinase, a specific inhibitor of the BCR-ABL fusion protein, commonly referred to as a tyrosine kinase inhibitor (TKI) [6, 9-12]. If patients are receptive and responsive to TKI treatment they are likely to survive in excess of 20 years after diagnosis and patients may have an average lifespan of 67 years of age [6,9-12]. In the case of patients who don't respond to TKI's (which is usually about $20 \%$ of patients) the disease progresses rapidly in $50 \%$ of these patients into the more aggressive acute or blastic phase. In these cases second, third and fourth generation TKI's are used for treatment as well as haematopoietic stem cell transplants $[6,9-12]$. In the other $50 \%$ of patients, CML progressively advances to the accelerated phase which may last for months or even years before progressing to the blastic phase [5]. Once the blastic transformation has occurred in patients their survival may only be 3-9 months [6, 9-12].

\section{Platelets}

Platelets are known to serve as a means for tumours to increase growth and provide physical- and mechanical support to elude the immune system and metastasize $[16,17]$. There is, however, no literature available on the role that platelets play in CML progression. Due to the fact that platelets fulfil an important role in cancer- and tumour development, their role in CML and potential influence in CML progression are of clinical significance.

Cancer metastasis is directly linked to platelet activity and, in particular, the ability of cancer cells to elude the immune system by formation of platelet-tumour aggregates [18-22]. The latter takes place through the binding of cancer cells (lung-, bone- and breast cancer) to P-selectin and integrins expressed on the membrane of platelets, thus activating the platelets [22].

Binding of cancer cells to platelets via P-selectin consequently results in attraction of platelets to areas of neovascularization and tumour growth by the release of serotonin and thromboxane from platelets [23]. Serotonin is known to have a tumour-stimulatory role and also 
contributes to cancer-related fatigue, while thromboxane stimulates proliferation and prevents apoptosis of cancer cells [23]. Mitogens including vascular endothelial growth factor (VEGF), platelet derived growth factor (PDGF) and transforming growth factor (TGF) are subsequently released thereby increasing vascularization and growth of the tumour [22-29].

Further activation of platelets ensues from the original tumour; triggering enhanced growth of the tumour as a result of the release of platelets granules [19]. Release of the contents of the granules from platelets hinders the ability of the immune surveillance system against malignancy through cloaking tumour cells and protecting the tumour cells from natural killer (NK) cells by providing a physical barrier and also placing major histocompatibility complex (MHC) class I antigen into the vicinity of the tumour cell surface $[8,30]$. This process is referred to as the platelet-cancer loop (Fig. 3) [31].

In a recent publication it was shown that platelets are not solely produced in the bone marrow as conventionally thought, but that platelet biogenesis is predominantly located in the lungs, producing approximately $50 \%$ of the total platelets in the circulation [32]. Furthermore, substantial populations of haematopoietic progenitors were found to be produced in the lungs. These progenitors could repopulate the bone marrow in cases of thrombocytopenia and stem cell deficiency [32]. These significant findings demonstrate that there are uncertainties concerning the process of haematopoiesis and specifically

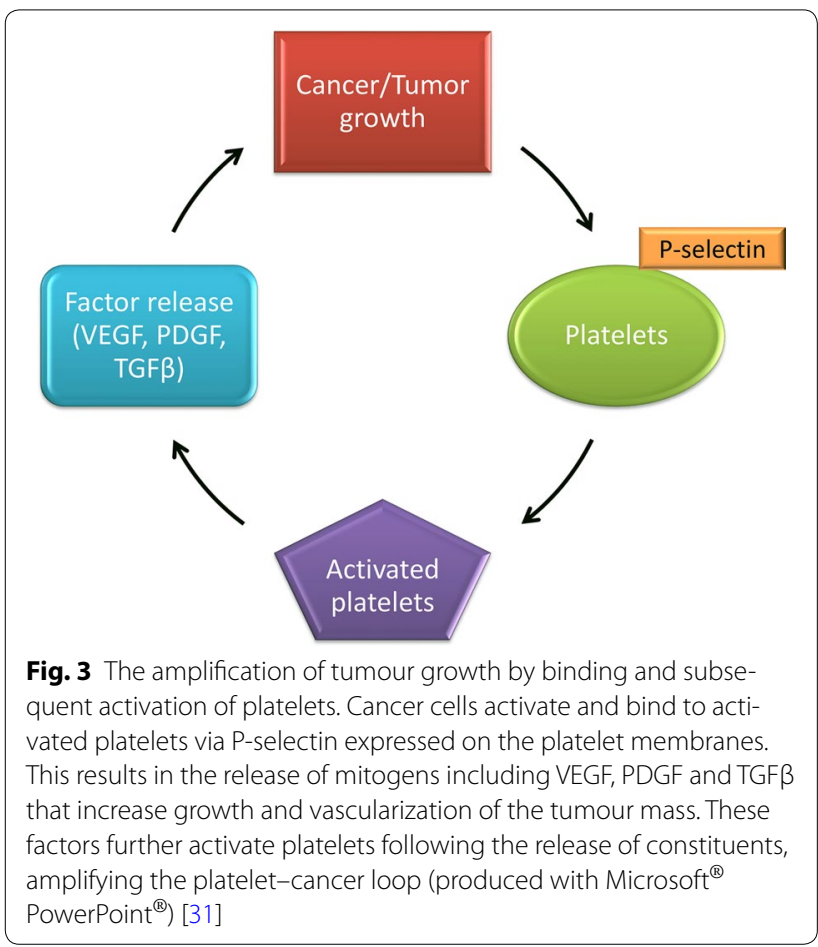

how this new source of haematopoiesis may affect our understanding of the aetiology of leukaemia [32].

Platelets play an important role in cancer and tumour development, in particular their direct involvement in the process of angiogenesis in tumours. Therapy directed at specifically targeting angiogenesis is a recognized method of treatment, however, it is not well researched in haematological malignancies [33]. The importance of angiogenesis-targeted therapies in CML has recently become clear as the occurrence of TKI resistance and specifically Imatinib resistance increases (Fig. 4).

Failure of patients to respond to Imatinib treatment can be a result of acquired resistance ensuing from mutations in the BCR-ABL 1 tyrosine kinase domain, loss of response and poor tolerance [33]. In CML, this resistance has recently become linked to bone marrow (BM) angiogenesis which aids in the growth and survival of leukaemia cells [33]. However, with the discovery of the lungs as a site of haematopoietic progenitors, this may indicate that CML resistance is not localized to the bone marrow and that the mutations leading to the disease and resistance to treatment may also occur in the haematopoietic progenitors in the lungs [32].

\section{Angiogenesis}

Angiogenesis is a well-known contributor to cancer progression and is defined as a closely-controlled biological process which takes place during foetal development of blood vessels and wound healing [34]. Angiogenesis is a process associated with the formation of new vascular sections onto a pre-existing vascular system $[35,36]$.

Tumour angiogenesis, the process leading to the formation of new blood vessels within the tumour mass, provides cancer cells with oxygen and nutrition and plays a central role in cancer cell survival $[35,36]$. It also promotes tumour growth and possible development of distant metastases [34-36].

The angiogenesis-related proteins released during angiogenesis can be differentiated into the angiogenic activators and the angiogenic inhibitors [30, 37]. Angiogenesis-activating proteins include VEGF, PDGF and matrix metallopeptidase-9 (MMP-9), while the angiogenic inhibitors include transforming growth factor $\beta$ $(\mathrm{TGF} \beta)[30,37,38]$. These angiogenesis-regulatory factors are released from activated platelets in circulating blood of patients with cancer or the development of tumours [38-40].

VEGF is a dimeric glycoprotein and a member of the PDGF family which contributes to angiogenesis by promoting endothelial cell growth, maturation and survival, enhancing vascular permeability and inhibiting apoptosis [41-44]. A wide variety of human tissues express low levels of VEGF (around 108 pg/ml) [41-44]. High levels 


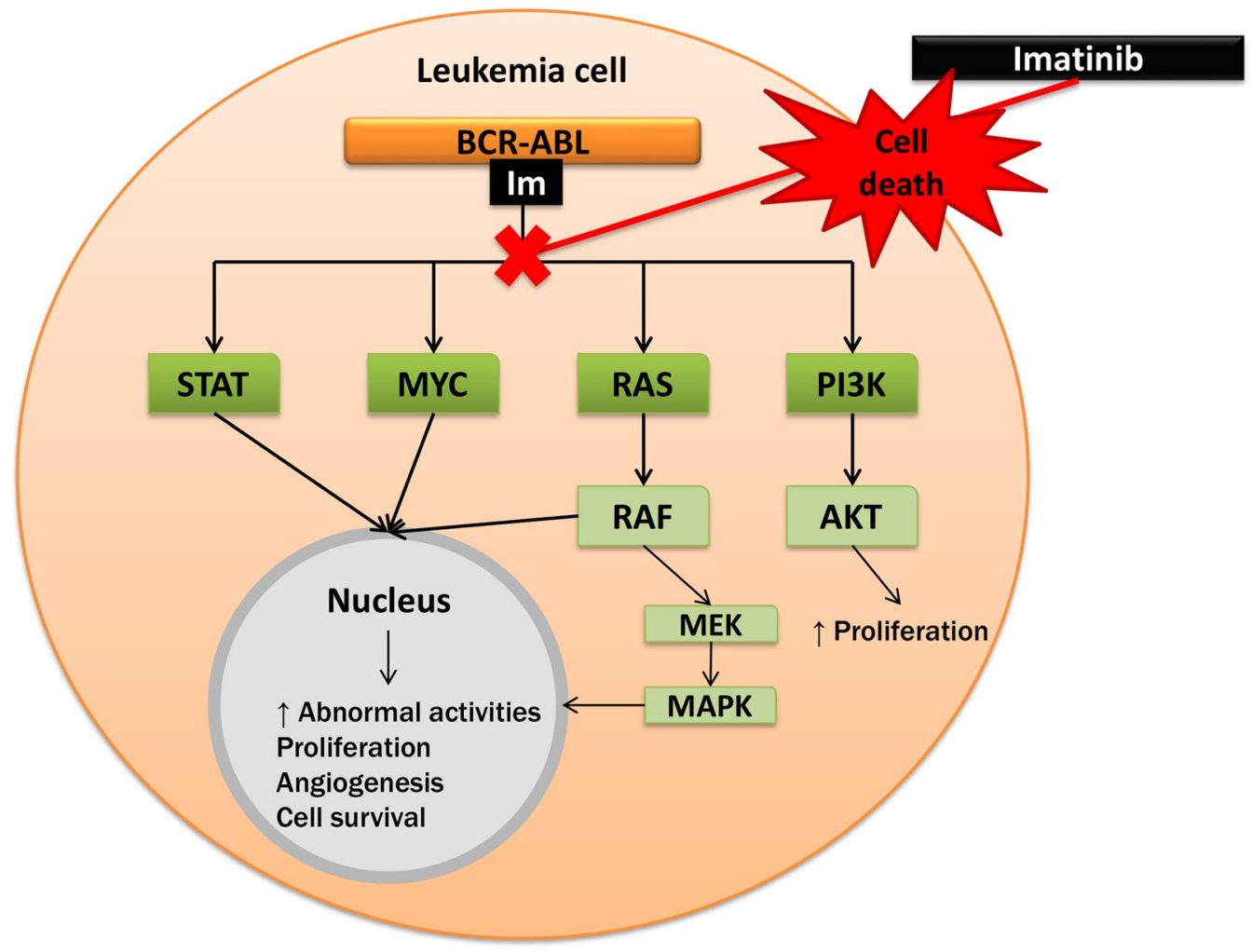

Fig. 4 Signal transduction pathway of the $B C R-A B L$ fusion gene and Imatinib action. Imatinib selectively inhibits the tyrosine kinase activity that is responsible for the signaling pathway illustrated through tyrosine kinase phosphorylation of these interactions. Main signaling pathways associated with the oncogenic activity of the BCR-ABL gene is MYC, RAS, MAPK, STAT and PI3K. These pathways result in the inhibition of gene transcription, mitochondrial processing of apoptotic reactions and cytoskeletal organization culminating in an increase in abnormal cell activities including unimpeded proliferation, angiogenesis and enhanced cell survival. When Imatinib binds to the tyrosine kinase receptor it in turn deactivates these pathways resulting in cell death of the mutated leukemic cell (produced with Microsoft ${ }^{\circledR}$ PowerPoint ${ }^{\circledR}$ ) $[9-11,33]$

(around $238 \mathrm{pg} / \mathrm{ml}$ ) are produced where angiogenesis is required such as in foetal tissue, the placenta, the corpus luteum, as well as in the vast majority of human tumours including breast, colorectal, bladder and ovarian cancers [45]. Studies have shown that prostate- and colorectal cancer patients have increased serum VEGF levels when compared to healthy individuals $[36,46,47]$.

It was reported that TGF $\beta$, another angiogenic-regulating factor released by platelets, also plays a role in the inhibition of the antitumour activity of T-cells, NK cells, neutrophils, monocytes and macrophages involved in regulating cancer progression [48].

PDGF is present in a number of cells including platelets, fibroblasts, keratinocytes, myoblasts, astrocytes, epithelial cells and macrophages [45]. Expression of PDGF and platelet derived growth factor receptors (PDGFRs) are dynamic and characterized by a constant change in levels; their biosynthesis and processing are controlled at various levels where increased expression or levels are indicative of several diseases and pathological conditions which are categorized into three causative disease groups namely tumours, vascular diseases and fibrosis [49].

Levels of PDGF, however, can be upregulated by a variety of stimuli including hypoxia, thrombin, cytokines and growth factors such as TGF $\beta$ [49]. Studies have shown increased PDGF signalling in epithelial types of cancer which affected tumour growth, angiogenesis, invasion and metastasis [49]. This may be explained by the fact that both PDGFR- $\alpha$ and PDGFR- $\beta$ engage in signaling pathways namely RAS-MAPK and PI3K known to be involved in cellular- and developmental responses including stimulation of cell growth, differentiation and migration [49].

The process of angiogenesis (Fig. 5) is thought to be primarily caused by hypoxia in tumours which activate hypoxia-inducible factor-1 (HIF-1) [35]. HIF-1 is responsible for increased expression of pro-angiogenic genes including VEGF [34]. VEGF mediates the process of angiogenesis through vasodilation of pre-existing blood vessels via generation of nitric oxide [34]. VEGF is a main 
Tumour mass

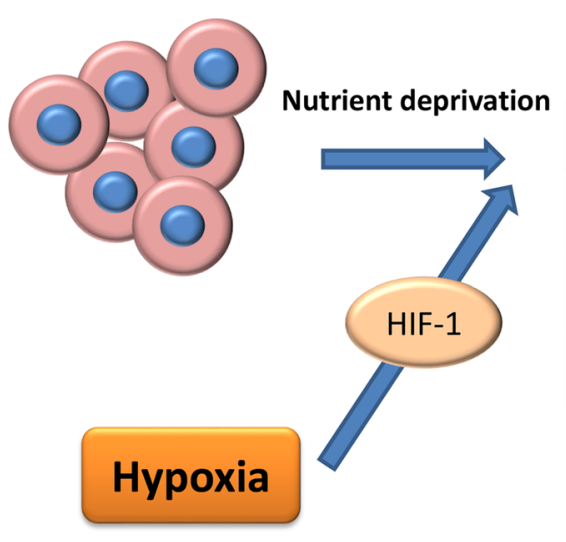

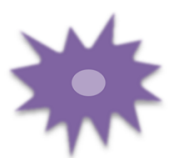

Fibroblast recruitment

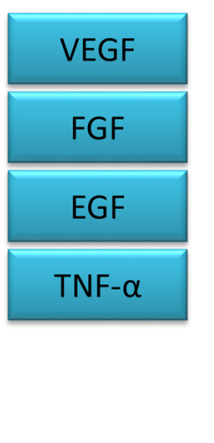

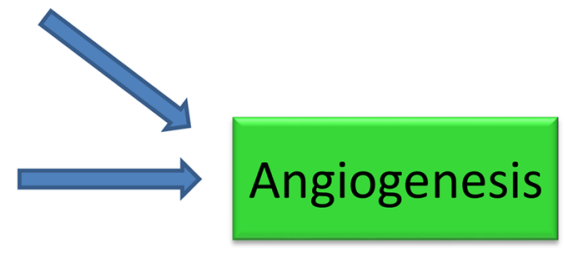

Proliferation of endothelial cells from nearby blood vessels

Fig. 5 Angiogenesis in cancer. Nutrient deprivation and hypoxia signal the necessity of oxygen and nutrients to the tumour mass and thus activate the process of angiogenesis through increased expression of proangiogenic genes including via HIF-1. This includes VEGF which results in vasodilation of pre-existing blood vessels via generation of nitric oxide, EGF, Ang1 and bFGF which stimulates proliferation, migration and assembly of the endothelium. Integrins $a_{v} \beta_{3}$ and $a_{5}$ mediate cell migration and spreading and PDGF recruits smooth muscle cells for the formation of a new basement membrane of forming vessels (produced with Microsoft ${ }^{\circledR}$ PowerPoint ${ }^{\circledR}$ ) [34]

contributor to angiogenesis by promoting endothelial cell growth, maturation and survival, enhances vascular permeability and inhibits apoptosis [36, 43, 44].

Nutrient deprivation within a tumour mass also signals the release of various angiogenic molecules [16, 17, 4550]. The release of VEGF, epidermal growth factor (EGF), angiopoietin 1 (Ang1) and basic fibroblastic growth factor (bFGF) stimulates proliferation, migration and assembly of the endothelium, while integrins $\alpha_{\mathrm{v}} \beta_{3}$ and $\alpha_{5}$ mediate cell migration and spread [34-36]. Formation of a new basement membrane is essential in maturation of newly formed vessels which takes place through recruitment of smooth muscle cells via PDGF [41].

Most of the above-mentioned angiogenesis-regulatory factors are released specifically from the $\alpha$-granules of platelets, which also play a role in vascular repair and cell to cell interactions [37]. Platelets contain 3 types of secretory granules including $\alpha$-granules, dense granules and lysosomes. It has, however, been shown that platelets can release either pro-angiogenic factors or antiangiogenic factors differentially in response to various tissue stimuli [37]. This suggests that platelets may hold clinical implications once the mechanism of differentiating release of pro- and anti-angiogenic factors is elucidated to target specific release of antiangiogenic factors at tumour sites [37].

\section{Cell death: apoptosis}

Many endogenous angiogenesis inhibitors have been shown to induce apoptosis in vivo [51]. Apoptosis is characterised by membrane blebbing, cell shrinkage, hypercondensation of chromatin and formation of apoptotic bodies, activated by either the intrinsic and/or the extrinsic pathways $[52,53]$. Both of these pathways include the interaction of death receptors with death ligands and activation of caspases (Fig. 6). These can be divided into two classes namely the initiator caspases (caspase 8 or 9) and the executioner caspases (caspase 3, 6, and 7) [54, 55].

In nucleated cells, the intrinsic apoptosis pathway is initiated by stimuli which trigger cytochrome $c$ to be released from the mitochondria, and, in turn recruit's initiator caspase 9, thereby activating executioner caspase 3 resulting in apoptosis [56]. During the extrinsic apoptotic 


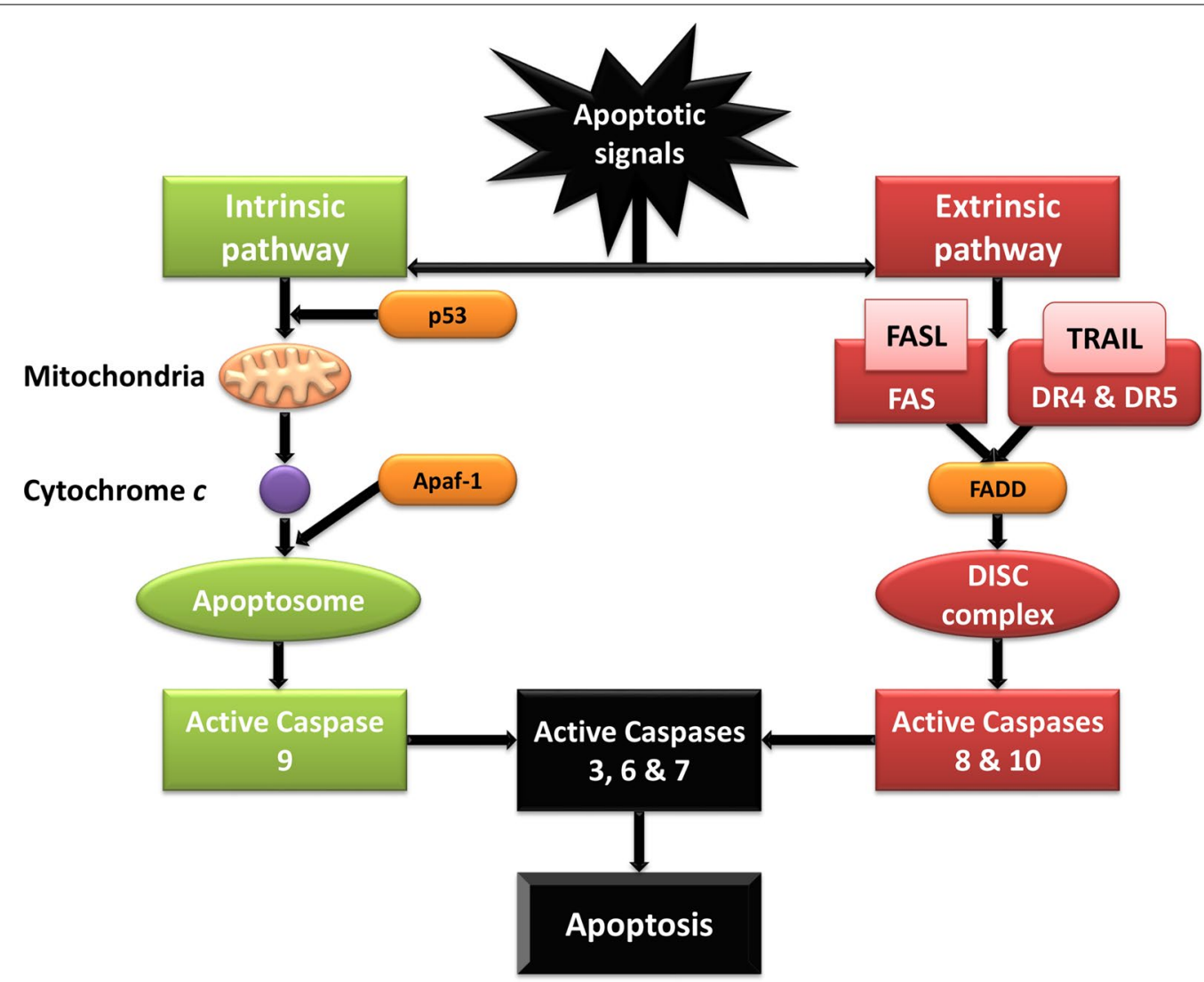

Fig. 6 Graphical representation of the intrinsic and extrinsic apoptotic pathway. The intrinsic apoptotic pathway is represented in green, indicating the release of cytochrome $c$ into the cytoplasm from the mitochondria following apoptotic signals to the cell. Following its release, cytochrome $c$ binds to apoptotic protease activating factor 1 (Apaf-1) forming the apoptosome which in turn recruits procaspase 9 . Procaspase 9 binds to the apoptosome activating caspase 9 which sequentially activates the effector caspases 3, 6 and 7 resulting in the execution phase of apoptosis. The extrinsic apoptotic pathway is shown in red and depicts the interaction of DRs with their corresponding death ligands following death signals to the cell. The binding of the death ligands to their DRs results in the release of adaptor molecules such a Fas-associated death domain (FADD) which employs inactive procaspases 8 and 10, forming the DISC and subsequent activation of the effector caspases resulting in apoptosis (produced with Microsoft ${ }^{\circledR}$ PowerPoint ${ }^{\circledR}$ ) [54-58]

pathway in nucleated cells, death receptors (DRs) including DR5 bind to death ligands which employ the initiator caspases 8 and 9 , forming the death-inducing signalling complex (DISC) and activation of the effector caspase 3 , ensuing in apoptosis $[52,57,58]$.

The removal of apoptotic cells is a result of phosphatidylserine (PS) collecting on the external layer of the cell membrane which is initiated by activation of the calcium-dependent phospholipid scramblase and signals macrophages to stimulate the removal of the apoptotic cells [56]. Once the PS has been externalized, a distinct characteristic of apoptosis, it is possible to quantify the extent of the PS-flip as binding sites are revealed during the flip [59].

Apoptosis is closely associated with occurrences within the nucleus and is consequently questioned in platelets since they lack this cellular component [60,
61]. Platelets display characteristic signs of nucleated apoptosis including membrane blebbing, loss of the integrity of the platelet membrane and microparticle release $[60,61]$. The ability of platelets to undergo apoptosis is a result of mitochondrial presence which contributes to mitochondrial deoxyribonucleic acid (DNA) and messenger ribonucleic acid (mRNA). Mitochondrial DNA and mRNA aid in the platelets' ability to synthesise proteins contained within platelet granules [62-64].

Thus, even though platelets do not possess a nucleus, they exhibit biological apoptotic signals during stressed conditions including activation of caspase 3 and exposure/externalisation of phosphatidylserine $[65,66]$. Kile [67] showed that platelets do undergo apoptosis via the intrinsic apoptotic pathway that also regulates the platelets' lifespan. 
The intrinsic apoptotic pathway in platelets, comparable to the process in nucleated cells, is characterised by activation of Bak and Bax, members of the B-cell lymphoma 2 (Bcl-2) protein family which promote apoptosis, triggering damage of the mitochondria and releasing cytochrome $c$ and other apoptotic proteins from the mitochondrial intermembrane space. The release of cytochrome $c$ allows for the formation of the Apaf-1 apoptosome and subsequent recruitment of initiator procaspase 9 . Binding to the apoptosome activates caspase 9 and leads to the activation of effector caspase 3 , culminating in the execution phase of apoptosis [58]. Upstream of caspase 3 activation and PS exposure, the mitochondrial inner transmembrane potential is depolarized in platelets, similar to the mechanism of nucleate cellular apoptosis (which is the programmed process of apoptosis in nucleated cells) $[64,68]$.

The resulting externalisation of PS then allows for removal of apoptotic platelets. In platelets, PS is also expressed on the cell surface, however, it can only be recognized by macrophages for phagocytosis by recognition via human cluster of differentiation 36 (CD36) present on the membrane of human platelets [65-69]. The externalisation of PS in platelets seems to also occur independently of the intrinsic apoptotic pathway playing an important role in formation of thrombin by assembling the pro-thrombinase complex [66-68].

\section{Cell death: autophagy}

In addition to apoptosis in platelets, the role of autophagy and the biological markers, including autophagy-related proteins (Atg) and quantification of the conversion of light chain 3-I (LC3-I) to LC3-II have not been researched extensively in platelets. Since platelets do contain small amounts of functional mitochondria, it has been proposed to share characteristics of nucleated autophagy mechanisms and markers (Fig. 7) [66]. Autophagy's ability to maintain cellular homeostasis and adjustment to starvation is of importance in platelets as their lifespan is only about 10 days in humans $[69,70]$. Autophagy can also be triggered continuously under certain stressed conditions such as starvation, cellular injury and contact

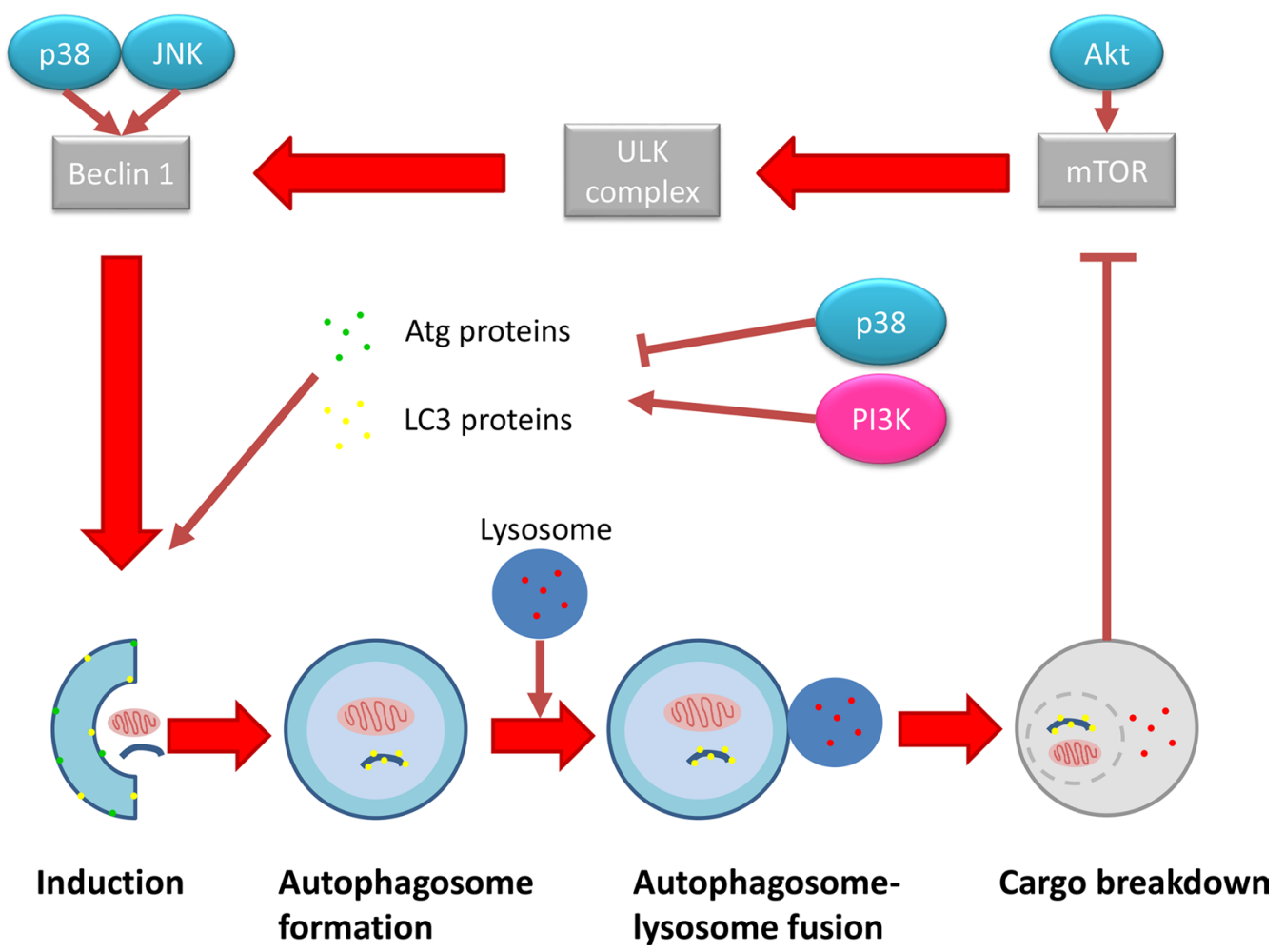

Fig. 7 Overview of autophagy in cells. Autophagy is activated through starvation signals stimulating Akt and thus inactivating mammalian target of rapamycin (mTOR) by detaching it from the uncoordinated 51 -like kinase (ULK) complex which in turn activates the ULK complex. Beclin-1 is subsequently activated recruiting Atg proteins necessary for autophagosome formation. These Atg proteins aid in employing and converting LC3-I to LC3-II by conjugation to phosphatidylethanolamine (PE) and Atg3 and 7. Upon the formation of the autophagosome, it fuses with lysosomes forming the autolysosome, wherein breakdown of the cargo takes place to recycle amino acids and fatty acid for further energy generation (produced with Microsoft ${ }^{\circledR}$ PowerPoint $\left.{ }^{\circledR}\right)[69,70]$ 
with certain chemicals such as lithium, which leads the cell to progressively degrade vital cytoplasmic components, essentially digesting itself $[69,70]$.

The occurrence of autophagy in platelets is essential in maintaining homeostasis within platelets and in the number of platelet populations [71]. The incidence of autophagy is not well documented in platelets. Literature has shown that platelets do express Atg proteins and the process is also activated by the inhibition of mTOR [71, 72]. A defect in platelet autophagy may result in compromised platelet adhesion and aggregation impacting on coagulation and the resulting formation of a platelet plug during damage to blood vessels [71].

\section{Conclusion}

CML patients have abnormal megakaryocytes that can deliver unusual blast fragments to the peripheral blood and patients are frequently found to have large and heterogeneous platelets. Additionally, TKI treatment has been shown to induce platelet dysfunction and may result in coagulation abnormalities and an increased incidence of bleeding [73-76]. Since platelets are significantly affected during CML progression and treatment, investigation into the role that platelets play in CML progression is of importance, including how treatment effects the cell death mechanisms of platelets. In light of new research implicating the lungs as an additional production site not only for platelets, but also haematopoietic progenitors, research into platelet involvement in CML is of critical importance.

\begin{abstract}
Abbreviations
ABL1: Abelson murine leukaemia viral oncogene homolog 1; AKT: protein kinase B; ALL: acute lymphoblastic leukaemia; AML: acute myeloid leukaemia; Ang1: angiopoietin 1; Apaf-1: apoptotic protease activating factor 1; Atg: autophagy-related genes; BCl-2: B cell lymphoma 2; BCR: breakpoint cluster region protein; bFGF: basic fibroblastic growth factor; $B M$ : bone marrow; $C D$ : cluster of differentiation; CLL: chronic lymphocytic leukaemia; CML: chronic myeloid leukaemia; Crkl: Crk-like protein; DISC: death-inducing signaling complex; DNA: deoxyribonucleic acid; DRs: death receptors; EGF: epidermal growth factor; FADD: Fas-associated death domain; HIF-1: hypoxia-inducible factor-1; Jnk: c-Jun N-terminal kinase; LC3: light chain-3; MAPK: mitogen activated protein kinases; Mek 1/2: mitogen-activated protein kinase 1/2; MHC: major histocompatibility complex; MMP-9: matrix metallopeptidase-9; mRNA: messenger ribonucleic acid; mTOR: mammalian target of rapamycin; NK: natural killer; PDGF: platelet derived growth factor; PDGFRs: platelet derived growth factor receptors; PE: phosphatidylethanolamine; Ph: Philadelphia; PI3K: phosphatidylinositol 3-kinase; PS: phosphatidylserine; RAS: rat sarcoma; RASMAPK: rat sarcoma mitogen-activated protein kinase; STAT: signal transducer and activator of transcription; TGF $\beta$ : transforming growth factor $\beta$; TKI: tyrosine kinase inhibitor; ULK: uncoordinated 51-like kinase; VEGF: vascular endothelial growth factor.
\end{abstract}

\section{Authors' contributions}

$L R$ was responsible for literature review and the main contributor to drafting of the manuscript. RP, MK, GT and AMJ assisted in drafting of the manuscript. All authors read and approved the final manuscript.

\begin{abstract}
Author details
${ }^{1}$ Department of Physiology, Faculty of Health Sciences, School of Medicine, University of Pretoria, Pretoria, Gauteng, South Africa. ${ }^{2}$ Department of Haematology, Faculty of Health Sciences, School of Medicine, University of Pretoria, Pretoria, Gauteng, South Africa. ${ }^{3}$ Department of Internal Medicine, Faculty of Health Sciences, School of Medicine, University of Pretoria, Pretoria, Gauteng, South Africa.
\end{abstract}

\section{Funding and Acknowledgements}

The financial assistance of the National Research Foundation, Struwig-Germeshuysen Research Trust, Medical Research Council of South Africa, the Cancer Association of South Africa and the School of Medicine Research Committee of the University of Pretoria is hereby acknowledged.

\section{Competing interests}

The authors declare that they have no competing interests.

Availability of data and materials

Data sharing is not applicable to this article as no datasets were generated or analysed during the current study.

\section{Consent for publication \\ Not applicable.}

Ethics approval and consent to participate

Not applicable.

\section{Publisher's Note}

Springer Nature remains neutral with regard to jurisdictional claims in published maps and institutional affiliations.

Received: 24 June 2017 Accepted: 29 October 2017

Published online: 10 October 2017

\section{References}

1. Jemal A, Bray F, Center MM, Ferlay J, Ward E, Forman D. Global cancer statistics. CA Cancer J Clin. 2011;61:69-90.

2. Kamangar F, Dores GM, Anderson WF. Patterns of cancer incidence, mortality, and prevalence across five continents: defining priorities to reduce cancer disparities in different geographic regions of the world. J Clin Oncol. 2006;24(14):2137-50.

3. Siegel R, DeSantis C, Virgo K, Stein K, Mariotto A, Smith T, Cooper D, Gansler T, Lerro C, Fedewa S, Lin C, Leach C, Cannady RS, Cho H, Scoppa S, Hachey M, Kirch R, Jemal A, Ward E. Cancer treatment and survivorship statistics, 2012. CA Cancer J Clin. 2012;62(4):220-41.

4. National Cancer Institute. What you need to know about leukemia (pamphlet). U.S. Department of Health and Human Service; 2013. NIH Publication No. 13-3775.

5. Hoffbrand AV, Catovsky D, Tuddenham EGD, Green AR, editors. Postgraduate haematology. 6th ed. Hoboken: Wiley; 2011.

6. American Cancer Society. Cancer facts \& figures 2014. Atlanta: American Cancer Society; 2014.

7. Patel AK, Zhang M, Huang X. Leukemia therapy: mechanisms of drug resistance and investigational strategies. Br J Med Med Res. 2014:4(24):4134-53.

8. Ntziachristos P, Mullenders J, Trimarchi T, Aifantis I. Mechanisms of epigenetic regulation of leukemia onset and progression. Adv Immunol. 2013. doi:10.1016/B978-0-12-410524-9.00001-3.

9. Sawyers CL. Chronic myeloid leukemia. N Engl J Med. 1999;340(17):1330-40.

10. Faderl S, Talpaz M, Estrov Z, O'Brien S, Kurzrock R, Kantarjian HM. The biology of chronic myeloid leukemia. N Engl J Med. 1999;341(3):164-72.

11. Goldman JM, Melo JV. Chronic myeloid leukemia_advances in biology and new approaches to treatment. N Engl J Med. 2003;349(15):1451-64.

12. Hehlmann R, Hochhaus A, Baccarani M. Chronic myeloid leukaemia. Lancet. 2007;370:342-50. 
13. Howlader N, Noone AM, Krapcho M, Miller D, Bishop K, Altekruse SF, Kosary CL, Yu M, Ruhl J, Tatalovich Z, Mariotto A, Lewis DR, Chen HS, Feuer EJ, Cronin KA. SEER cancer statistics review, 1975-2013, National Cancer Institute. Bethesda, MD, http://seer.cancer.gov/csr/1975_2013/, based on November 2015 SEER data submission, posted to the SEER web site, April 2016.

14. Bessman JD, Williams LJ, Gilmer PR. Platelet size in health and hematologic disease. Am J Clin Pathol. 1982;78(2):150-3.

15. Quintás-Cardama A, Han X, Kantarjian H, Cortes J. Tyrosine kinase inhibitor-induced platelet dysfunction in patients with chronic myeloid leukemia. Blood. 2009:114(2):261-3.

16. Jain S, Harris J, Ware J. Platelets: linking hemostasis and cancer. Arterioscler Thromb Vasc Biol. 2010;30(12):2362-7.

17. Trikha M, Zhou Z, Timar J, Raso E, Kennel M, Emmell E, et al. Multiple roles for platelet GPIIb/IIla and alphavbeta3 integrins in tumor growth, angiogenesis, and metastasis. Cancer Res. 2002;62(10):2824-33.

18. Jackson SP, Schoenwaelder SM. Procoagulant platelets: are they necrotic? Blood. 2010;116(12):2011-8.

19. Nash GF, Turner LF, Scully MF, Kakkar AK. Platelets and cancer. Lancet Oncol. 2002;3(7):425-30

20. Riedl J, Pabinger I, Ay C. Platelets in cancer and thrombosis. Hamostaseologie. 2014;34(1):54-62.

21. Gay LJ, Felding-Habermann B. Platelets alter tumor cell attributes to propel metastasis: programming in transit. Cancer Cell. 2011;20(5):553-4.

22. Sharma D, Brummel-Ziedins KE, Bouchard BA, Holmes CE. Platelets in tumor progression: a host factor that offers multiple potential targets in the treatment of cancer. J Cell Physiol. 2014;229(8):1005-15.

23. Troxler M, Dickinson $\mathrm{K}$, Homer-Vanniasinkam S. Platelet function and antiplatelet therapy. Br J Surg. 2007:94(6):674-82.

24. Erpenbeck L, Schön MP. Deadly allies: the fatal interplay between platelets and metastasizing cancer cells. Blood. 2010;115(17):3427-36.

25. Bambace NM, Holmes CE. The platelet contribution to cancer progression. J Thromb Haemost. 2011:9(2):237-49.

26. Whiteheart SW. Platelet granules: surprise packages. Blood. 2011;118(5):1190-1.

27. Blair P, Flaumenhaft R. Platelet a-granules: basic biology and clinical correlates. Blood Rev. 2009;23(4):177-89.

28. King SM, Reed GL. Development of platelet secretory granules. In: Seminars in cell \& developmental biology. Cambridge: Academic Press; 2002

29. McNicol A, Israels SJ. Platelet dense granules: structure, function and implications for haemostasis. Thromb Res. 1999;95(1):1-18.

30. Sabrkhany S, Griffioen AW, Oude Egbrink MG. The role of blood platelets in tumor angiogenesis. Biochim Biophys Acta. 2011;1815(2):189-96.

31. Goubran HA, BurnoufT, Radosevic M, El-Ekiaby M. The platelet-cancer loop. Eur J Intern Med. 2013;24(5):393-400.

32. Lefrançais E, Ortiz-Muñoz G, Caudrillier A, Mallavia B, Liu F, Sayah DM, Thornton EE, Headley MB, David T, Coughlin SR, Krummel MF. The lung is a site of platelet biogenesis and a reservoir for haematopoietic progenitors. Nature. 2017:544(7648):105-9.

33. Schmidt T, Carmeliet P. Angiogenesis: a target in solid tumors, also in leukemia? ASH Educ Progr B. 2011:1:1-8.

34. Folkman J, Shing Y. Angiogenesis. J Biol Chem. 1992;267(16):10931-4.

35. Yue TL, Wang X, Louden CS, Gupta S, Pillarisetti K, Gu JL, et al. 2-Methoxyestradiol, an endogenous estrogen metabolite, induces apoptosis in endothelial cells and inhibits angiogenesis: possible role for stressactivated protein kinase signaling pathway and Fas expression. Mol Pharmacol. 1997:51(6):951-62

36. Ciardiello F, Caputo R, Bianco R, Damiano V, Fontanini G, Cuccato S, et al. Inhibition of growth factor production and angiogenesis in human cancer cells by ZD1839 (Iressa), a selective epidermal growth factor receptor tyrosine kinase inhibitor. Clin Cancer Res. 2001;7(5):1459-65.

37. Italiano JE, Richardson JL, Patel-Hett S, Battinelli E, Zaslavsky A, Short S, et al. Angiogenesis is regulated by a novel mechanism: pro- and antiangiogenic proteins are organized into separate platelet alpha granules and differentially released. Blood. 2008;111(3):1227-33.

38. Sierko E, Wojtukiewicz MZ. Platelets and angiogenesis in malignancy. Semin Thromb Hemost. 2004;30(1):95-108.

39. Baj-Krzyworzeka M, Majka M, Pratico D, Ratajczak J, Vilaire G, Kijowski $J$, et al. Platelet-derived microparticles stimulate proliferation, survival, adhesion, and chemotaxis of hematopoietic cells. Exp Hematol. 2002;30(5):450-9.
40. Wartiovaara U, Salven P, Mikkola H, Lassila R, Kaukonen J, Joukov V, et al. Peripheral blood platelets express VEGF-C and VEGF which are released during platelet activation. Thromb Haemost. 1998;80(1):171-5.

41. Dunn IF, Heese O, Black PM. Growth factors in glioma angiogenesis: FGFs, PDGF, EGF, and TGFs. J Neurooncol. 2000;50(1-2):121-37.

42. Hall M, Gourley C, MCNeish I, Ledermann J, Gore M, Jayson G, et al. Targeted anti-vascular therapies for ovarian cancer: current evidence. $\mathrm{Br}$ J Cancer. 2013;108(2):250-8.

43. Lee CC, Liu KJ, Huang TS. Tumor-associated macrophage: its role in tumor angiogenesis. J Cancer Mol. 2006;2(4):135-40.

44. Plake KH, Warnke PC. Vascular endothelial growth factor. J Neurooncol. 1997;35:365-72.

45. Papetti M, Herman IM. Mechanisms of normal and tumor-derived angiogenesis. Am J Physiol Cell Physiol. 2002;282(5):C947-70.

46. Peterson J, Zurakowski D, Italiano J, Michel L, Connors S, Oenick M, et al. VEGF, PF4 and PDGF are elevated in platelets of colorectal cancer patients. Angiogenesis. 2012;15(2):265-73.

47. Duque JL, Loughlin KR, Adam RM, Kantoff PW, Zurakowski D, Freeman MR. Plasma levels of vascular endothelial growth factor are increased in patients with metastatic prostate cancer. Urology. 1999:54(3):523-7.

48. Bierie B, Moses HL. Transforming growth factor beta (TGF-ß) and inflammation in cancer. Cytokine Growth Factor Rev. 2010:21:49-59.

49. Andrae J, Gallini R, Betsholtz C. Role of platelet-derived growth factors in physiology and medicine. Genes Dev. 2008;22(10):1276-312.

50. Yoon SO, Park SJ, Yun CH, Chung AS. Roles of matrix metalloproteinases in tumor metastasis and angiogenesis. J Biochem Mol Biol. 2003;36(1):128-37.

51. Tiwari M. Apoptosis, angiogenesis and cancer therapies. J Cancer Res Ther. 2012;1(1):3.

52. Mukhopadhyay T, Roth JA. Induction of apoptosis in human lung cancer cells after wild-type p53 activation by methoxyestradiol. Oncogene. 1997;14:379-84.

53. Pasquier $\mathrm{E}$, Kavallaris M. Microtubules: a dynamic target in cancer therapy. IUBMB Life. 2008;60(3):165-70.

54. Dobos J, Timar J, Bocsi J, Burian Z, Nagy K, Barna G, et al. In vitro and In vivo antitumor effect of 2-methoxyestradiol on human melanoma. Int J Cancer. 2004;112:771-6.

55. Vorster C, Joubert A. In vitro effects of 2-methoxyestradiol-bis-sulphamate on cell growth, morphology and cell cycle dynamics in the MCF-7 breast adenocarcinoma cell line. Biocell. 2010;34(2):71-9.

56. Choi HJ, Zhu BT. Critical role of cyclin B1/Cdc2 up-regulation in the induction of mitotic prometaphase arrest in human breast cancer cells treated with 2-methoxyestradiol. Biochim Biophys Acta. 2012;1823:1306-15.

57. Stander XX, Stander BA, Joubert AM. In vitro effects of an in silico modelled $17 \beta$-estradiol derivative in combination with dichloroacetic acid on MCF-7 and MCF-12A cells. Cell Prolif. 2011:44:567-81.

58. Du B, Zhao Z, Sun H, Ma S, Jin J, Zhang Z. Effects of 2-methoxyestradiol on proliferation, apoptosis and gene expression of cyclin B1 and c-Myc in esophageal carcinoma EC9706 cells. Cell Biochem Funct. 2012;30:158-65.

59. Stander BA, Joubert F, Joubert A. Docking, synthesis, and in vitro evaluation of antimitotic estrone analogs. Chem Biol Drug Des. 2011;77(3):173-81.

60. Rendu F, Brohard-Bohn B. The platelet release reaction: granules' constituents, secretion and functions. Platelets. 2001;12(5):261-73.

61. Li J, Xia Y, Bertino AM, Coburn JP, Kuter DJ. The mechanism of apoptosis in human platelets during storage. Transfusion. 2000;40(11):1320-9.

62. Reed GL. Platelet secretory mechanisms. In: Seminars in thrombosis and hemostasis. New York: Thieme Medical Publishers, Inc.; 2004.

63. Zharikov S, Shiva S. Platelet mitochondrial function: from regulation of thrombosis to biomarker of disease. Biochem Soc Trans. 2013;41(1):118-23.

64. Leytin V, Freedman J. Platelet apoptosis in stored platelet concentrates and other models. Transfus Sci. 2003;28(3):285-95.

65. Bertino AM, Qi XQ, Li J, Xia Y, Kuter DJ. Apoptotic markers are increased in platelets stored at 37 C. Transfusion. 2003;43(7):857-66

66. Zhao L, Zhang W, Chen M, Zhang J, Zhang M, Dai K. Aspirin Induces platelet apoptosis. Platelets. 2013;24(8):637-42.

67. Kile BT. The role of the intrinsic apoptosis pathway in platelet life and death. J Thromb Haemost. 2009;7(s1):214-7.

68. Leytin V. Apoptosis in the anucleate platelet. Blood Rev. 2012;26(2):51-63. 
69. Schrijvers DM, De Meyer GR, Herman AG, Martinet W. Phagocytosis in atherosclerosis: molecular mechanisms and implications for plaque progression and stability. Cardiovasc Res. 2007;73(3):470-80.

70. Hait WN, Jin S, Yang JM. A matter of life or death (or both): understanding autophagy in cancer. Clin Cancer Res. 2006;12(7):1961-5.

71. Feng W, Chang C, Luo D, Su H, Yu S, Hua W, Chen Z, Hu H, Liu W. Dissection of autophagy in human platelets. Autophagy. 2014;10(4):76-85.

72. Gottlieb RA. Autophagy in health and disease. Cambridge: Academic Press; 2012.

73. Hochhaus A, Larson RA, Guilhot F, Radich JP, Branford S, Hughes TP, Baccarani M, Deininger MW, Cervantes F, Fujihara S, Ortmann CE. Long-term outcomes of imatinib treatment for chronic myeloid leukemia. N Engl J Med. 2017;376(10):917-27.
74. Hoffmann VS, Hasford J, Deininger M, Cortes J, Baccarani M, Hehlmann R. Systematic review and meta-analysis of standard-dose imatinib vs. high-dose imatinib and second generation tyrosine kinase inhibitors for chronic myeloid leukemia. J Cancer Res Clin Oncol. 2017:1-8.

75. Chereda B, Melo JV. The Biology and Pathogenesis of Chronic Myeloid Leukemia. In: Chronic Myeloid Leukemia. Springer International Publishing. 2016:17-39.

76. Steegmann JL, Baccarani M, Breccia M, Casado LF, García-Gutiérrez V, Hochhaus A, Kim DW, Kim TD, Khoury HJ, Le Coutre P, Mayer J. European LeukemiaNet recommendations for the management and avoidance of adverse events of treatment in chronic myeloid leukaemia. Leukemia. 2016;30:1648-71

\section{Submit your next manuscript to BioMed Central and we will help you at every step:}

- We accept pre-submission inquiries

- Our selector tool helps you to find the most relevant journal

- We provide round the clock customer support

- Convenient online submission

- Thorough peer review

- Inclusion in PubMed and all major indexing services

- Maximum visibility for your research

Submit your manuscript at www.biomedcentral com/submit 